\title{
Analisis Pengaruh Toko Ritel Modern Terhadap Pendapatan Pedagang Tradisional dalam Perspektif Ekonomi Islam
}

\author{
Andi Triyawan \& Kurnia Firmanda Jayanti \\ Prodi Ekonomi Islam, Universitas Darussalam Gontor, Ngawi, Jawa Timur. \\ E-mail: andisurabaya85@gmail.com
}

\begin{abstract}
The aim of this research isto find out the influence of retail modern existence through traditional retail seller income at Subdistrict Ngawi Regency Ngawi and discover its solution in islamic economic. And giving some sugestion for retial traditional seller to evolving their business. This research is quantitativefield research, by obtaining primary source from questioner which had devided to traditional retail seller in subdistric Ngawi. The result is showing that, Sig in Coefficient table are about 0,433>0,05 which tell that Ho is rejected, which mean is, there is some effect between the existence of modern retailwith traditional retail seller income in subdistrict Ngawi. And with T-Test also showed that Ho is rejectedwith $\mathrm{t}$-count $<\mathrm{t}$ table $(-0,031<2,093)$. Then, we can conclude regresion equation $\mathrm{Y}^{\prime}=4,539-0,031 \mathrm{X}+\mathrm{e}$, which means, if the exixtence of modern retail is valued 0 , then the income of traditional retail seller is valued 4,539. Because of regresion coefficient the existence of modern retail is about $-0,031$, then every additional one unit of modern retail will affect to decrease of traditional retail seller income about $\mathrm{Rp} 0,031$.
\end{abstract}

Keywords: Modern Retail, Traditional retail, Islamic Economics.

\section{Pendahuluan}

Upaya manusia untuk memenuhi kebutuhannya sudah berlangsung sejak manusia itu ada. Salah satu kegiatan manusia dalam usaha memenuhi kebutuhan tersebut adalah jual-beli, dimana pasar berperan sebagai sarana pendukungnya. ${ }^{1}$ Untuk itu, pasar merupakan kegiatan ekonomi yang termasuk salah satu perwujudan adaptasi manusia terhadap lingkungannya. Maka, selama ini pasar sudah menyatu dan memiliki tempat paling penting dalam kehidupan masyarakat sehari-hari, bagi masyarakat pasar bukan hanya tempat bertemunya

\footnotetext{
1 Nahdliyul Izza, "Pengaruh Pasar Modern Terhadap Pedagang Pasar Tradisional (Studi Pengaruh Ambarukmo Plaza Terhadap Perekonomian Pedagang Pasar Desa Caturtunggal Nologaten Depok Sleman Yogyakarta”, dalam Skripsi Jurusan Pengembangan Masyarakat Islam, Fakultas Dakwah, Universitas Islam Negeri Sunan Kalijaga Yogyakarta, 2010, hal.16.
} 
antara penjual dan pembeli tetapi juga sebagai wadah untuk berinteraksi sosial. Seperti yang telah dideskripsikan para Ekonom, bahwa sebuah pasar merupakan kumpulan penjual dan pembeli yang melakukan transaksi atas suatu produk tertentu atau kelompok produk tertentu ${ }^{2}$ Pasar menurut manajemennya dapat dibedakan menjadi dua macam, yaitu pasar tradisional dan pasar modern, dimana kedua pasar tersebut memiliki keunggulan dan kelemahan masing-masing. Disisi lain masyarakat Indonesia memiliki selera belanja yang multimode, yang artinya dalam sesaat berbelanja ke pasar tradisional dan sesaat kemudian berbelanja di pasar modern. ${ }^{3}$

Dalam perekonomian, juga dikenal istilah retail atau yang lebih akrab disebut dengan perdagangan eceran. Bisnis Retail di Indonesia mengalami perkembangan yang cukup pesat pada beberapa tahun terakhir ini, dengan berbagai format dan jenisnya. Hal ini diakibatkan oleh adanya perkembangan usaha manufaktur dan peluang pasar yang cukup terbuka, maupun upaya pemerintah untuk mendorong perkembangan bisnis retail melalui peraturan pemerintah dan undang-undang. ${ }^{4}$ Selain Pasar Modern dan Pasar Tradisional, ada juga istilah Retail Modern dan Retail Tradisional Adapun contoh dari Retail Modern adalah Alfamart, Indomaret dan juga Minimarket lain yang menyerupainya. Sedang contoh dari Retail Tradisional adalah toko kelontong, warung tradisional dan juga toko-toko kecil yang membuka usaha di depan rumahnya.Barang yang dijual di Retail Modern maupun di Retail Tradisional tidaklah berbeda, mulai dari kebutuhan rumah tangga harian, makanan ringan dan minuman. ${ }^{5}$ Namun pada kenyataannya masyarakat yang lebih memilih berbelanja di Retail Modern daripada di Retail Tradisional, dengan berbagai pertimbangan, seperti kenyamanan, kebersihan dan kualitas barang yang terdapat di Retail Modern.

Selain itu disparitas harga di Retail Modern tidak terpaut jauh dengan Retail Tradisional. Dan juga jarak Retail Modern yang sangat dekat dengan Retail Tradisional, serta perubahan pola berbelanja masyarakat akan menimbulkan dampak tersendiri bagi pedagang Retail Tradisional yang menjual barang dagangan yang sama dengan yang ada di Retail Modern. Maka dari itu, tidak hanya Ekonomi Indonesia yang memperhatikan masalah diatas, melainkan juga Ekonomi Islam. ${ }^{6}$ Seperti yang kita ketahui bahwa sistem ekonomi Islam adalah

\footnotetext{
${ }^{2}$ Muhammad Aziz Hakim, Menguasai Pasar Mengeruk Untung, (Jakarta: PT Krisna Persada, 2005), hal. 67.

${ }^{3}$ Rasidin Karo-Karo Sitepu, "Dampak Keberadaan Pasar Modern Terhadap Kinerja Ekonomi Regional”, dalam Jurnal QE Journal, (No. 01, Vol. 01) hal.1.

${ }^{4}$ Christina Whidya Utami, "Manajemen Ritel: Strategi dan Implementasi Operasional Bisnis Modern di Indonesia”, (Salemba Empat: Jakarta, 2010, Edisi 2), hal. 24

5 Ronald Sihotang, Syaad Afifudin dan Rahmanta, "Pengaruh Pasar Modern Terhadap Pedagang Retail Tradisional dan Masyarakat dalam Pengembangan Wilayah di Kecamatan Medan Area", dalam Jurnal Ekonom (No. 4, Vol.17, Oktober 2014), hal.182.

${ }^{6}$ Hafiz Juliansyah, "Faktor-faktor yang Mempengaruhi Etika Bisnis Islam Pedagang Pasar Ciputat", dalam Skripsi Jurusan Perbankan Syariah, Fakultas Syari'ah dan Hukum, Universitas Islam Negeri Syari Hidayatullah Jakarta, 2011, hal.2.
} 
perekonomian tiga sektor, yaitu pasar, masyarakat dan negara. Pasar mendapat kedudukan yang penting dalam perekonomian Islam, Islam menolak konsep pasar dalam bentuk persaingan bebas tanpa batas sehingga mengabaikan norma dan etika. Aktivitas pasar harus mencerminkan persaingan yang sehat, jujur, terbuka dan adil sehingga harga yang tercipta adalah harga yang adil. ${ }^{7}$ Selain itu, Islam juga menegaskan bahwa pasar harus berada diatas prinsip persaingan sempurna (perfect competition). Namun demikian bukan berarti keebasan tersebut berlaku mutlak, akan tetapi kebebasan yang dibungkus oleh frame syari'ah. Dalam Islam, transaksi terjadi secara sukarela sebagaimana disebutkan dalam (QS. An-Nisa[4]: 29),

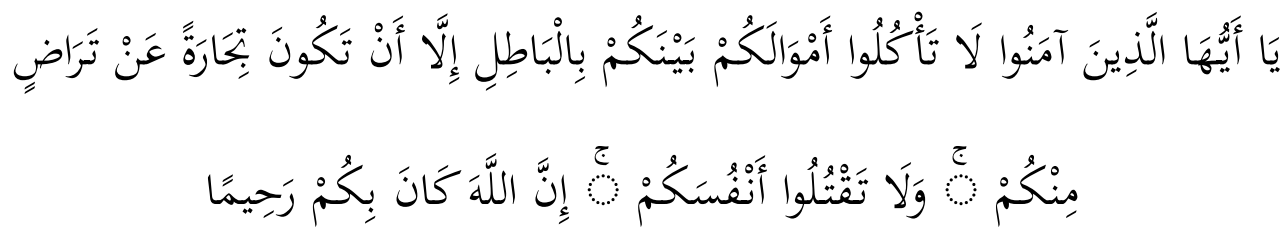

Artinya: Hai orang-orang yang beriman, janganlah kamu saling memakan harta sesamamu dengan jalan yang batil, kecuali dengan jalan perniagaan yang berlaku dengan suka sama-suka di antara kamu. Dan janganlah kaтu membunuh dirimu; sesungguhnya Allah adalah Maha Penyayang kepadamu.

Dari kenyataan diatas, peneliti tertarik untuk meneliti dampak keberadaan Retail Modern terhadap pendapatan pedagang Retail Tradisional di Kecamatan Ngawi Kabupaten Ngawi dan solusinya dalam Ekonomi Islam.Disinilah peneliti akan mengadakan penelitian yang berjudul "Analisis Dampak Retail Modern Terhadap Pendapatan Pedagang Retail Tradisional dan Solusinya dalam Ekonomi Islam (Studi Kasus Di di Kecamatan Ngawi Kabupaten Ngawi).

\section{Pengertian Pasar}

Dalam kamus Ekonomi \& Bisnis dinyatakan bahwa, "Pasar merupakan tempat terjadinya penawaran dan permintaan antara penjual yang ingin menukarkan barang-barangnya dengan uang dan pembeli yang ingin menukarkan uangnya dengan barang dan jasa". ${ }^{8}$ Oleh karena itu, setiap orang yang membeli barang tertentu dari sorang penjual, dan pembeli bisa mendapatkan kebutuhan dan keinginannya dari barang dagangan penjual, maka penjual sudah bisa dikatakan telah mengadakan pasar. Dalam Ilmu Ekonomi, pasar tidak hanya diartikan sebagai suatu tempat di mana pada hari tertentu para penjual dan para pembeli dapat bertemu untuk jual-beli barang, melainkan sebagai suatu pertemuan antara orang yang mau menjual dan orang yang mau membeli suatu barang atau jasa

\footnotetext{
${ }^{7}$ Adiwarman Karim, Ekonomi Mikro Islam, (Jakarta: PT. Raja Grafindo, 2007), hal. 91.

8 Waluyo Hadi \& Dini Hastuti, Kamus Terbaru Ekonomi dan Bisnis, (Surabaya: Reality Publisher, 2011), hal.364-365.
} 
tertentu dengan harga tertentu. ${ }^{9}$ Menurut manajemennya, pasar dapat dibagi menjadi dua, ${ }^{10}$ pertama, pasar tradisional adalah pasar yang bersifat tradisional, dimana penjual dan pembeli mengadakan tawar-menawar secara langsung. Barang yang diperjual-belikan adalah barang pokok. kedua, pasar modern adalah pasar yang bersifat modern, dimana barang-barang yang diperjual-belikan dengan harga pas dan layanan mandiri (swalayan), contohnya; mall, hypermarket, plaza.

\section{Pengertian Retail Modern dan Retail Tradisional}

Kata Retail berasal dari bahasa Perancis Ritellier, yang berarti memotong atau memecah sesuatu. ${ }^{11}$ Retail bisa disebut juga dengan penjualan barang secara eceran, bisnis retail merupakan suatu bisnis menjual produk dan jasa pelayanan yang telah diberi nilai tambah untuk memenuhi kebutuhan pribadi, keluarga atau pengguna akhir lainnya. ${ }^{12}$ Retail mempunyai beberapa fungsi, yang dimana bermanfaat bagi produsen dan juga konsumen, yaitu : ${ }^{13}$ (1) Menyediakan berbagai macam produk dan jasa; (2) Memecah; (3) Perusahaan penyimpan persediaaan; (4) Penghasil jasa; (5) Meningkatkan nilai produk dan jasa.

Selain mempunyai fungsi, retail juga mempunyai beberapa jenis diantaranya: ${ }^{14}$ pertama, Retail Toko yang menjual barang dagangan konsumsi rumah tangga dan bisnis. Berlokasi di tempat yang strategis agar bisa menarik banyak konsumen, contohnya; toko alat tulis kantor dan toko komputer. kedua, Retail Khusus yang menjual barang-barang sekunder atau tersier, dimana fokus mereka terletak pada peningkatan kenyamanan lingkungan rumah tangga. ketiga, retail Non-Toko yang merupakan sektor retail yang mempromosikan barang dagangannya melalui televisi, perbelanjaan elektronik, kertas dan katalog elektronik. Semua itu dapat digunakan oleh setiap konsumen dengan sangat mudah, tanpa harus mendirikan sebuah tempat ataupun bangunan untuk menawarkan barang dagangan mereka.

Bisnis Retail di Indonesia dibedakan menjadi dua, yaitu Retail Modern dan Retail Tradisional. Retail Modern pada dasarnya merupakan pengembangan dari Retail Tradisional, format Retail ini muncul dan berkembang seiring perkembangan perekonomian, teknologi dan gaya hidup masyarakat yang menuntut kenyamanan lebih dalam berbelanja. ${ }^{15}$ Persaingan antara Retail Modern

\footnotetext{
9 T. Gilarso, Pengantar Ilmu Ekonomi Makro, (Yogyakarta : Kanisius, 2004), hal. 109

${ }^{10}$ Eka Yuliasih, "Studi Eksplorasi Dampak Keberadaan Pasar Modern Terhadap Usaha Ritel Waserda dan Pedagang Pasar Tradisional di Kecamatan Klirong Kabupaten Kebumen”, dalam Skripsi Jurusan Pendidikan Ekonomi, Fakultas Ekonomi Universitas Negeri Yogyakarta, 2013, hal.11.

${ }^{11}$ Christina Whidya Utami, "Manajemen Ritel : Strategi dan Implementasi Operasional Bisnis Modern di Indonesia”, (Salemba Empat : Jakarta, 2010, Edisi 2), hal.5.

12 Danang Sunyoto, "Manajemen Bisnis Ritel. Teori, Praktik dan Kasus Ritel", (CAPS : Yogyakarta, 2015), hal. 1.

${ }^{13}$ Ibid, hal. 12-14

${ }^{14}$ Danang Sunyoto, Op.Cit., hal. 8-13

15 Dianna Sari Untung, "Potensi Private Label dalam Menarik Minat Konsumen pada Bisnis Retail", Jurnal tidak diterbitkan.
} 
dan Retail Tradisional terjadi antara jenis Retail dalam ukuran yang kurang lebih sama, contohnya seperti keberadaan minimarket dengan toko dan kios disekitarnya dan juga pasar tradisional dengan supermarket atau hypermarket. Ketiga jenis Retail Modern, yaitu Minimarket, Supermarket dan Hypermarket mempunyai karakteristik yang sama dalam model penjualan, yaitu dilakukan secara eceran langsung pada konsumen kahir dengan cara swalayan, artinya pembeli mengambil sendiri barang dari rak-rak dagangan dan membayar di kasir. ${ }^{16}$

Sedang Retail Tradisional berupa toko, kios, los dan tenda yang dimiliki atau dikelola oleh pedagang kecil, menengah, swadaya masyarakat atau koperasi dengan usaha kecil, modal kecil dan dengan proses jual beli barang dengan melalui tawar menawar. Hal inilah yang menjelaskan bahwa Retail Tradisional kalah bersaing dengan Retail Modern, namun bukan berarti bahwa Retail Modern tidak mempunyai kelemahan yang dapat dimanfaatkan Retail Tradisional sebagai celah agar dapat bersaing secara kompetitif, karena Retail Tradisional juga memiliki beberapa keunggulan. ${ }^{17}$ Adapun keunggulan Retail Modern yaitu memiliki bentuk yang menarik, memiliki kenyamanan dalam ruang dan kebersihan, elayanan yang baik kepada pembeli, selalu memunculkan promo baru dalam produk yang disertai potongan harga (diskon), dilakukan penyaringan yang ketat terhadap produk yang dijual, sehingga dari segi kualitas tidak perlu dikhawatirkan lagi.Adapun kelemahannya adalah harga pas sehingga tidak bisa ditawar dan sebagian pelayan tidak ramah atau tidak sopan.Begitu juga Retail Tradisional yang memiliki keunggulan dapat bersahabat dengan pembeli, kadang harga bisa ditawar, bisa berhutang dan dibayar kemudian dan dekat dengan rumah. Adapun juga kelemahannya adalah bentuk toko tidak menarik, tata letak barang didalam toko tidak diatur dengan nyaman, tidak selalu memperhatikan kenyamanan dan kebersihan, barang tidak lengkap, kurang penerangan lampu dan juga kurang modal.

Perbedaan mencolok antara Retail Tradisional dan Retail Modern terletak pada sistem dan pelayanannya. ${ }^{18}$ Pada Retail Tradisional barang-barang kecil kerap dipajang pada etalase kaca yang kemudian akan menutupi sebagian besar ruang belanja, sehingga pembeli tidak bisa leluasa dalam pemilihan barang yang akan dibelinya. Sedangkan pada Retail Modern, semua barang dipajang pada rak-rak atau etalase besar sehingga pembeli dapat langsung memilih barang yang mereka inginkan. Namun tingkat kehilangan barang yang tinggi tidak bisa dihindari oleh

\footnotetext{
16 Tri Joko Utomo, "Persaingan Bisnis Retail : Tradisional Vs Modern", dalam Jurnal Fokus Ekonomi, (Vol.6, No.1, Juni, 2011), hal. 125.

${ }^{17}$ Yoga dan Dendy, Op. Cit., hal.13-14. Dan lihat juga Faisal Basri, "Perekonomian Indonesia, Tantangan dan Harapan Bagi Kebangkitan Indonesia".

18 Arif Rahman, Rockin' Ur Retail Business, Modern Retail Handbook@Small Bisnis, (Yogyakarta : Andi, 2010), hal. 9-11
} 
retail Modern, untuk itu mereka selalu berusaha untuk meningkatkan keamanan toko mereka.

\section{Metode Penelitian}

Penelitian yang akan dilakukan oleh peneliti termasuk dalam penelitian lapangan yang bersifat kuantitatif asosiatif dengan hubungan kausal. Metode ini dipilih oleh peneliti untuk menanyakan hubungan antara dua variabel atau lebih yang bersifat sebab-akibat. Satu variabel sebagai variabel independen dan variabel yang lain sebagai variabel yang dependen. ${ }^{19}$ Adapun populasi yang akan diambil peneliti sebagai bahan penelitian adalah pedagang retail tradisional yang ada di Kecamatan Ngawi. Sampel yang digunakan sebesar 20 orang yang diambil berdasarkan Convenience Sampling, dimana peneliti mengambil sampel berdasarkan yang menyenangkan saja atau berdasarkan faktor spontanitas.

Untuk teknik pengumpulan data dilakukan melalui observasi, kuesioner, wawancara dan dokumentasi. Observasi yang digunakan adalah observasi terus terang, dimana peneliti menyatakan dengan terus terang kepada sumber data, tetapi dalam suatu saat, peneliti juga tidak terus terang untuk menghindari kalau suatu data yang dicari merupakan data yang masih dirahasiakan. Begitu juga kuesioner merupakan beberapa pertanyaan pilihan yang nantinya akan diajukan kepada pedagang retail tradisional di Kecamatan Ngawi. Wawancara yang digunakan peneliti adalah wawancara terstruktur dimana peneliti menggunakan pedoman wawancara yang telah tersusun secara sistematis dan lengkap untuk pengumpulan datanya. Dan untuk dokumentasi dapat berbentuk tulisan dan gambar yang didapatkan peneliti selama penelitian.

\section{Analisis dan Pembahasan}

Dari hasil kuesioner yang didapatkan peneliti, peneliti menghitung kevalidan setiap butir pertanyaan yang ia ajukan kepada para pedagang retail tradisional di Kecamatan Ngawi Kabupaten Ngawi menggunakan SPSS 15.00.

\section{Case Processing Summary}

\begin{tabular}{|ll|r|r|}
\hline & & \multicolumn{1}{|c|}{$\mathrm{N}$} & \multicolumn{1}{|c|}{$\%$} \\
\hline Cases & Valid & 20 & 100,0 \\
& Excluded(a) & 0 &, 0 \\
& Total & 20 & 100,0 \\
\hline
\end{tabular}

a Listwise deletion based on all variables in the procedure

\footnotetext{
${ }^{19}$ Sugiyono, Metode Penelitian Bisnis, (Bandung : Alfabeta, 2010), hal.55-56
} 
Reliability Statistics

\begin{tabular}{|c|c|}
\hline Cronbach's Alpha & $\mathrm{N}$ of Items \\
\hline ,759 & 9 \\
\hline
\end{tabular}

Item-Total Statistics

\begin{tabular}{|l|r|r|r|r|}
\hline & $\begin{array}{r}\text { Scale Mean if } \\
\text { Item Deleted }\end{array}$ & $\begin{array}{r}\text { Scale Variance } \\
\text { if Item Deleted }\end{array}$ & $\begin{array}{r}\text { Total } \\
\text { Correlation }\end{array}$ & \multicolumn{2}{c|}{$\begin{array}{c}\text { Cronbach's Alpha if } \\
\text { Item Deleted }\end{array}$} \\
\hline p1 & 29,70 & 17,484 &, 402 &, 742 \\
p2 & 29,95 & 16,682 &, 562 &, 723 \\
P3 & 29,45 & 16,787 &, 473 &, 733 \\
P4 & 29,35 & 17,082 &, 485 &, 732 \\
P5 & 29,40 & 16,568 &, 453 &, 735 \\
P6 & 29,10 & 18,726 &, 397 &, 749 \\
P7 & 29,30 & 17,274 &, 454 &, 736 \\
P8 & 29,50 & 16,368 &, 552 &, 722 \\
P9 & 29,80 & 14,484 &, 473 &, 739 \\
\hline
\end{tabular}

Dengan menggunakan jumlah responden sebanyak 20 responden,maka nilai $\mathrm{r}$ tabel dapat diperoleh melalui tabel $\mathrm{r}$ product moment pearson dengan $\mathrm{df}$ $($ degree of freedom $)=n-2$, jadi $\mathrm{df}=20-2=18$, maka $\mathrm{r}$ tabel $=0,378$. Butir pertanyaan dinyatakan valid apabila nilai $r$ hitung $>r$ tabel. Dari hasil perhitungan SPSS 15.0, bisa diketahui bahwa semua variabel dikatakan valid dan akan dimasukkan kedalam penghitungan Regresi untuk selanjutnya. Adapun Uji Reliabilitas dapat dilihat pada nilai Cronbach's Alpha, jika nilai Alpha $>0,60$, maka kontruk pertanyaan yang merupakan dimensi variabel adalah Reliabel. Dari hasil diatas didapatkan hasil 0,795 untuk Nilai Cronbach's Alpha, jadi dapat disimpulkan bahwa pertanyaan yang telah diajukan peneliti semuanya Reliabel. 
Model Summary(b)

\begin{tabular}{|l|r|r|r|r|r|}
\hline Model & $\mathrm{R}$ & R Square & R Square & $\begin{array}{c}\text { Adjusted } \\
\text { Estimate }\end{array}$ & Durbin-Watson \\
\hline 1 &, $102(\mathrm{a})$ &, 010 &,- 045 &, 749 & 2,220 \\
\hline
\end{tabular}

a Predictors: (Constant), y

b Dependent Variable: $\mathrm{x}$

$\operatorname{ANOVA}(b)$

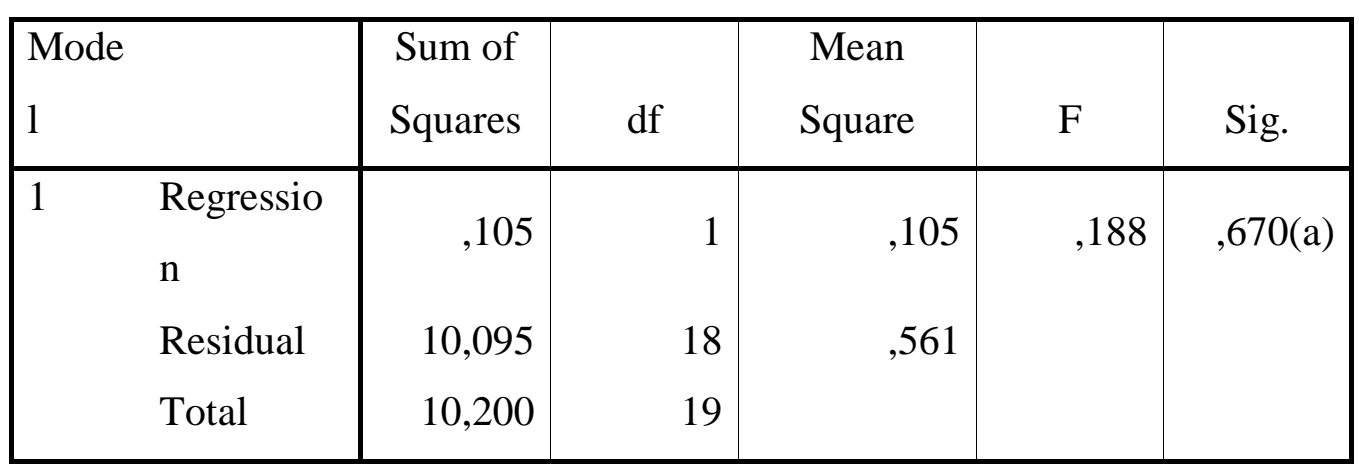

a Predictors: (Constant), y

b Dependent Variable: $\mathrm{x}$

Coefficients(a)

\begin{tabular}{|c|c|c|c|c|c|c|c|}
\hline \multirow[t]{2}{*}{$\begin{array}{l}\text { Mo } \\
\text { del }\end{array}$} & \multicolumn{2}{|c|}{$\begin{array}{c}\text { Unstandardized } \\
\text { Coefficients }\end{array}$} & \multirow[t]{2}{*}{$\begin{array}{l}\text { Standardize } \\
\text { d } \\
\text { Coefficients }\end{array}$} & \multirow{2}{*}{\begin{tabular}{|c|}
$\mathrm{T}$ \\
Tolera \\
nce
\end{tabular}} & \multirow{2}{*}{$\begin{array}{l}\text { Sig. } \\
\text { VIF }\end{array}$} & \multicolumn{2}{|c|}{$\begin{array}{c}\text { Collinearity } \\
\text { Statistics }\end{array}$} \\
\hline & B & $\begin{array}{l}\text { Std. } \\
\text { Error }\end{array}$ & & & & B & $\begin{array}{l}\text { Std. } \\
\text { Error }\end{array}$ \\
\hline $\begin{array}{ll}1 & \text { (Const } \\
\text { ant) }\end{array}$ & 4,539 & 1,944 & & 2,335 & ,031 & & \\
\hline$Y$ &,- 031 & 071 &,- 102 &,- 433 & ,670 & 1,000 & 1,000 \\
\hline
\end{tabular}

a Dependent Variable: $\mathrm{x}$

Dari analisis data yang telah dilakukan oleh peneliti menggunakan Analisis Regresi Sederhana dengan bantuan SPSS 15.0, bisa disimpulkan bahwa keberadaan retail modern mempunyai pengaruh negatif terhadap pendapatan pedagang retail tradisional. Hal ini dibuktikan dengan Sig pada tabel Koefisien sebesar 0,433>0,05 yang menyatakan bahwa Ho ditolak, yang berarti adanya pengaruh antara keberadaan retail modern dengan pendapatan pedagang retail tradisional. Dan juga dengan Uji T yang juga membuktikan penolakan Ho dengan $\mathrm{t}$ hitung $<\mathrm{t}$ tabel $(-0,031<2,093)$. Sehingga dapat disimpulkan juga persamaan regresi $\mathrm{Y}^{\prime}=4,359-0,031 \mathrm{X}+\mathrm{e}$, yang berarti jika keberadaan retail modern 
nilainya 0 , maka pendapatan pedagang retail tradisional bernilai 4,359 . Karena koefisien regresi keberadaan retail modern sebesar -0,031, maka setiap penambahan satu unit retail modern akan berdampak pada penurunan pendapatan pedagang retail tradisional sebesar $\mathrm{Rp} 0,031$.

\section{Perspektif Ekonomi Islam dalam Menanggulangi Dampak Keberadaan Retail Modern}

Terkait solusi ekonomi Islam dalam menanggulangi keberadaan retail modern, dengan merujuk pada kebijakan Presiden Republik Indonesia tentang Penataan dan Pembinaan Pasar Tradisional, Pusat Perbelanjaan dan Toko Modern dalam Peraturan Presiden Republik Indonesia Nomor 112 Tahun 2007. Untuk Penataan Pusat Perbelanjaan dan Toko Modern tertuang dalam Perpres No 112 Tahun 2007 Bab II Bagian Kedua Pasal 3. Sebenarnya, Pemerintah Indonesia pun sudah berusaha mengatur jarak antara Toko Modern dengan Toko Tradisional agar tidak saling berdekatan, dengan mengeluarkan Perpres yang telah disebutkan diatas. Upaya yang serupa juga telah dilakukan oleh Bupati Ngawi dalam Peraturan Daerah Kabupaten Ngawi Nomor 35 Tahun 2011 tentang Pengelolaan, Pembinaan dan Penataan Pasar. Oleh karena itu, dalam Ekonomi Islam pun juga dibahas bahwa unsur-unsur monopolistik dalam pasar harus dihilangkan, kolusi antara penjual dan pembeli juga harus dihilangkan, sehingga Pemerintah boleh melakukan intervensi apabila unsur monopolistik sudah terlihat. ${ }^{20}$ Maka, bisa dilihat bahwa ada keterkaitan antara kebijakan dalam Perpres Indonesia, Perda Ngawi dan Ekonomi Islam.

Semuanya tidak menghendaki adanya satu bagian ataupun kedua bagian saling tidak diuntungkan, dengan adanya keberadaan yang lain. Untuk itu, agar tidak terjadi banyak hal yang tidak diinginkan maka perlu untuk menunjuk seseorang atau suatu kelompok masyarakat yang mempunyai tugas pokok untuk mengawasi kelancaran dan keharmonisan dalam suatu pasar. Dalam istilah Ekonomi Islam lebih dikenal dengan istilah muhtasib. Sedangkan pekerjaannya dinamakan AlHisbah. Dalam arti luasnya, muhtasib bertugas menyelesaikan perkara-perkara yang berkaitan dengan al-amr bi al-ma'ruf wa nahy 'an al munkar, yang bukan hanya pekerjaan beberapa orang melainkan seluruh umat Islam. ${ }^{21}$ Namun dalam arti sempitnya mempunyai arti petugas yang bertugas mengawasi pasar serta tingkah laku masyarakat.Maka, pengawas atau Muhtasib bisa dijadikan solusi yang paling tepat dalam Ekonomi Islam untuk mengatasi masalah penurunan pendapatan pedagang retail tradisional dengan maraknya kehadiran retail modern, dengan mengatur jarak retail modern yang hendak mendirikan usahanya berdekatan dengan retail tradisional.

\footnotetext{
${ }^{20}$ Akhmad Mujahidin, Ekonomi Islam : Sejarah, Konsep, Negara dan Pasar, (Jakarta : Rajawali Press, Edisi Revisi, Cetakan ke-3, 2014), hal. 157-158

21 Rozalinda, Ekonomi Islam, Teori dan Aplikasinya pada Aktivitas Ekonomi, (Jakarta : Rajawali press, 2015), Cetakan ke-2, Edisi 1, hal. 175
} 


\section{Penutup}

Setelah diketahui hasil diatas, maka peneliti berusaha untuk mencari solusinya dalam Ekonomi Islam. Sebenarnya Presiden Republik Indonesia dan juga Bupati Ngawi telah mengeluarkan beberapa kebijakan perihal keberadaan retail modern yang tidak boleh berdekatan, namun masih banyak instansi yang tidak menghiraukan kebijakan ini.Untuk itu perlu ditunjuk beberapa orang atau sekelompok orang yang bertugas untuk mengawasi beberapa hal mengenai kendala yang dialami retail, pasar maupun toko. Dalam Islam, pengawas ini disebut dengan Muhtasib, yaitu orang yang bertugas untuk mengawasi dan mengontrol kelancaran dan keharmonisan pasar. Berdasarkan analisis yang telah dilakukan oleh peneliti menggunakan Analisis Regresi Sederhana dengan bantuan SPSS 15.0, bisa disimpulkan bahwa keberadaan retail modern mempunyai pengaruh negatif terhadap pendapatan pedagang retail tradisional. Hal ini dibuktikan dengan Sig pada tabel Koefisien sebesar 0,433>0,05 yang menyatakan bahwa Ho ditolak, yang berarti adanya pengaruh antara keberadaan retail modern dengan pendapatan pedagang retail tradisional. Dan juga dengan Uji T yang juga membuktikan penolakan Ho dengan $\mathrm{t}$ hitung $<\mathrm{t}$ tabel $(-0,031<$ 2,093). Sehingga dapat disimpulkan juga persamaan regresi $\mathrm{Y}^{\prime}=4,359-0,031 \mathrm{X}+$ e, yang berarti jika keberadaan retail modern nilainya 0, maka pendapatan pedagang retail tradisional bernilai 4,359. Karena koefisien regresi keberadaan retail modern sebesar $-0,031$, maka setiap penambahan satu unit retail modern akan berdampak pada penurunan pendapatan pedagang retail tradisional sebesar Rp 0,031.

\section{Daftar Pustaka}

Algifari. 2015.Analisis Regresi Untuk Bisnis dan Ekonomi. Yogyakarta. BPFE. Arikunto, Suharismi. 2013. Manajemen Penelitian. Jakarta. Rineka Cipta Gilarso, T. 2004.Pengantar Ilmu Ekonomi Makro. Yogyakarta. Kanisius.

Hadi, Waluyo \& Dini Hastuti. 2011. Kamus Terbaru Ekonomi dan Bisnis. Surabaya. Reality Publisher.

Hakim, Muhammad Aziz. 2015. Menguasai Pasar Mengeruk Untung. Jakarta. PT Krisna Persada.

Izza, Nahdliyul. "Pengaruh Pasar Modern Terhadap Pedagang Pasar Tradisional (Studi Pengaruh Ambarukmo Plaza Terhadap Perekonomian Pedagang Pasar Desa Caturtunggal Nologaten Depok Sleman Yogyakarta”. Skripsi Jurusan Pengembangan Masyarakat Islam, Fakultas Dakwah, Universitas Islam Negeri Sunan Kalijaga Yogyakarta. 2010.

Juliansyah, Hafiz. 2011. "Faktor-faktor yang Mempengaruhi Etika Bisnis Islam Pedagang Pasar Ciputat”. Skripsi Jurusan Perbankan Syariah, Fakultas 
Syari'ah dan Hukum, Universitas Islam Negeri Syari Hidayatullah Jakarta.

Karim, Adiwarman. 2007. Ekonomi Mikro Islam. Jakarta. PT. Raja Grafindo.

Lind, Douglas A. et.al. 2014. Teknik-teknik Statistika dalam Bisnis \& Ekonomi. Jakarta. Salemba Empat.

Mujahidin, Akhmad. 2014. Ekonomi Islam: Sejarah, Konsep, Negara dan Pasar. Jakarta. Rajawali Press.

Pusat Pengkajian dan Pengembangan Ekonomi Islam (P3EI) Universitas Islam Indonesia. 2008. Ekonomi Islam. Jakarta. Rajagrafindo Persada.

Rahman, Arif. 2010. Rockin' Ur Retail Business, Modern Retail Handbook @ Small Bisnis. Yogyakarta. Andi.

Rozalinda. 2015. Ekonomi Islam; Teori dan Aplikasinya pada Aktivitas Ekonomi. Jakarta. Rajawali Press.

Sihotang, Ronald. et.al. "Pengaruh Pasar Modern Terhadap Pedagang Retail Tradisional dan Masyarakat dalam Pengembangan Wilayah di Kecamatan Medan Area”. Jurnal Ekonom. No. 4, Vol.17, Oktober 2014.

Sitepu, Rasidin Karo-Karo. "Dampak Keberadaan Pasar Modern Terhadap Kinerja Ekonomi Regional”. Jurnal QE Journal. No. 01, Vol. 01.

Sugiyono. 2010. Metode Penelitian Bisnis. Bandung. Alfabeta.

Sujarweni, Wiratna. 2015. SPSS Untuk Penelitian. Yogyakarta. Pustaka Baru.

Sunyoto, Danang. 2015. Manajemen Bisnis Ritel. Teori, Praktik dan Kasus Ritel. CAPS. Yogyakarta, 2015.

Utami, Christina Whidya. 2010. Manajemen Ritel; Strategi dan Implementasi Operasional Bisnis Modern di Indonesia. Salemba Empat. Jakarta.

Utomo, Tri Joko. "Persaingan Bisnis Retail : Tradisional Vs Modern". Jurnal Fokus Ekonomi. Vol.6, No.1, Juni, 2011.

Yuliasih, Eka. "Studi Eksplorasi Dampak Keberadaan Pasar Modern Terhadap Usaha Ritel Waserda dan Pedagang Pasar Tradisional di Kecamatan Klirong Kabupaten Kebumen”. Skripsi Jurusan Pendidikan Ekonomi, Fakultas Ekonomi Universitas Negeri Yogyakarta, 2013.

Zimmerer, Thomas W. et.al. 2008. Kewirausahaan dan Manjemen Usaha Kecil. Jakarta. Salemba Empat. 